\title{
A AGRICULTURA CAMPONESA (DES)APARECERÁ FRENTE ÀS DETERMINAÇÕES DO CAPITAL E/OU SE (RE)CRIARÁ?
}

\section{A AGRICULTURA CAMPONESA (DES)APARECERÁ FRENTE ÀS DETERMINAÇÕES DO CAPITAL E/OU SE (RE)CRIARÁ?}

\author{
Sirlei Antoninha Kroth Gaspareto \\ Universidade de Santa Cruz do Sul - Santa Cruz do Sul - RS - Brasil \\ Erica Karnopp \\ Universidade de Santa Cruz do Sul - Santa Cruz do Sul - RS - Brasil \\ Cidonea Machado Deponti \\ Universidade de Santa Cruz do Sul - Santa Cruz do Sul - RS - Brasil
}

\begin{abstract}
Resumo: Discute-se neste artigo alguns aspectos relacionados ao debate sobre o (des)aparecimento da agricultura camponesa como um tema recorrente que ganha visibilidade em diferentes contextos e perspectivas teóricas com diferentes entendimentos, concepções e percepções. Esta discussão resulta de processos que estão em construção, vão sendo (re)significados e (re)elaborados pelos próprios sujeitos que permanentemente "se fazem" nas lutas por diferentes modos de vida e por sua vez, tais construções estão em disputa tanto no mundo acadêmico quanto no mundo político. Trabalha-se com a ideia de que mesmo considerando os conflitos e as contradições inerentes ao contexto rural, a agricultura camponesa ao invés de desaparecer, se reinventa e se fortalece. A revisão conceitual sobre o tema se dá a partir de uma leitura de autores clássicos como Lênin (1899/1985) Kautsky (1980) Shanin (2005) em diálogo com outros autores como: Lamarche $(1993,1998)$ e Abramovay (1992), Wanderley (1989), Oliveira (2004), Mendras (1976) Sandroni (1985). Busca-se na experiência do Movimento de Mulheres Camponesas em Santa Catarina os significados do termo camponês - camponesa, bem como, aspectos relativos à experiência das mulheres camponesas desse Movimento em relação à ressignificação da agricultura camponesa. Conclui-se que contrariamente ao que vem sendo afirmado historicamente, o modo de vida camponesa, ao invés de desaparecer, se (re)cria, se (re)inventa e se (re)coloca nos diferentes cenários enquanto modo de vida, de resistência e de enfrentamento às determinações do Capital.
\end{abstract}


Palavras-chave: campesinato, desenvolvimento rural, Movimento de Mulheres Camponesas de Santa Catarina

\begin{abstract}
It is discussed in this article some aspects of the debate on the (dis) appearance of peasant agriculture as a recurring theme that gained visibility in different contexts and theoretical perspectives with different understandings, conceptions and perceptions. This discussion, results of processes that are under construction, will be (re) meanings and (re) produced by the subjects themselves permanently "to do" in the struggle for different ways of life and in turn, these buildings are in dispute both academic world and the political world. Works with the idea that even considering the conflicts and contradictions inherent in the rural context, peasant agriculture instead of its demise, it reinvents itself and grows. The conceptual review on the subject is given from a reading of classical authors like Lenin (1899/1985) Kautsky (1980) Shanin (2005) in dialogue with other authors such as: Lamarche (1993.1998) and Abramovay (1992) Wanderley (1989), Oliveira (2004), Mendras (1976) Sandroni (1985). Search on the Movement of Peasant Women of experience in Santa Catarina the meanings of the term camponês - peasant, as well as aspects of the experience of peasant women of this movement in relation to the reframing of peasant agriculture. In conclusion, contrary to what has been said historically, the way of peasant life, instead of disappearing, (re) create, (re) invents and (re) places in the different scenarios as a way of life, resistance and coping with the determinations of the Capital.
\end{abstract}




\section{Introdução}

A problemática em torno do debate sobre o (des)aparecimento da agricultura camponesa é um tema recorrente e ganha visibilidade em diferentes contextos e perspectivas teóricas com diferentes entendimentos, concepções e percepções. Trata-se de processos que estão em construção, vão sendo (re)significados e (re)elaborados pelos próprios sujeitos que permanentemente "se fazem" nas lutas por diferentes modos de vida e por sua vez, tais construções estão em disputa tanto no mundo acadêmico quanto no mundo político.

A partir da década de 1990 os conceitos que tratam sobre camponês e agricultor familiar foram passando por alterações explicitadas por pesquisas e estudos que tratam da temática em diferentes áreas. Não há como negar de que autores clássicos como Marx e Lênin, colocaram em evidência a ideia da possibilidade do "desaparecimento" da vida camponesa frente às determinações do Capital. Entretanto, a discordância a este debate é colocada por diferentes autores que sinalizam para a continuidade da vida camponesa.

Este artigo tem como objetivo estabelecer uma breve reflexão sobre os fundamentos teóricos que tratam sobre a agricultura camponesa, diferenciando-a e ou aproximando-a do conceito de agricultura familiar, sem, contudo, ter a pretensão de esgotar a complexidade do tema.

Muito tem sido escrito sobre as categorias agrárias que abordam o tema da agricultura camponesa e familiar e sobre as contradições vividas frente ao processo de desenvolvimento do capitalismo no campo. Esse texto explicita o debate sobre como a categoria agricultura camponesa tem sido abordada e vem sendo (re)elaborada e (re)significada pelas mulheres do Movimento de Mulheres Camponesas (MMC), considerando que no espaço do Movimento, essas mulheres estudam, buscam compreender e ressignificar aspectos da experiência camponesa de seus antepassados, sobre os quais também vão recriando suas concepções e perspectivas.

O esforço reside na busca de compreensão sobre esse camponês, essa camponesa que se coloca enquanto criador (a) de suas alternativas de sobrevivência, muitas vezes, dizendo não e ou submetendo-se às 
determinações do capital. Inserindo-se em movimentos de luta por uma agricultura orgânica e agroecológica, vão produzindo para autossustento, criando outras perspectivas de relação com a natureza, com o ar, água, solo e entre os próprios seres humanos. Este camponês ao invés de contentar-se com a integração ao mercado resiste e se reorganiza na luta buscando criar outras formas de viver no campo.

Para tanto, dividiu-se o artigo em seções, conforme se descreve a seguir: Agricultura camponesa (des)aparecerá? Apresenta autores que abordam como única saída para o campesinato a mudança de camponês para agricultor familiar. Estes estão alinhados ao Centro Latino Americano de Desenvolvimento Regional vinculados ao Banco Mundial. Entre eles podemos citar: Lênin (1899/1985) e (1918/1980), Lamarche $(1993,1998)$ e Abramovay (1992).

Na seção: Um embate de ideias: agricultura camponesa se (re)cria e se (re)significa, autores como: Kautsky (1980), Wanderley (1989), Oliveira (2004), Shanin (2005), entre outros acreditam na ressignificação e na continuidade da agricultura camponesa principalmente pela capacidade de luta e de resistência dos camponeses frente às determinações do capital. Estes autores estão vinculados ao Centro Latino Americano de Ciências Sociais (CLACSO), articulados com a VIA CAMPESINA.

$\mathrm{Na}$ seção: Agricultura Familiar e camponesa: Aproximações e diferenças, entre os autores citados, destacam-se: Wanderley (1996), Mendras (1976) Sandroni (1985), Shanin (2005). Estes autores destacam o elemento familiar como principal característica tanto na agricultura camponesa como na agricultura familiar.

A seção: Agricultura Camponesa na perspectiva do MMC traça algumas considerações de como os conceitos vão sendo apropriados e ressignificados nos espaços de luta dos movimentos populares. Sendo que a quinta e última seção destaca alguns significados do termo camponês para o MMC.

Com esse estudo, obejetiva-se responder centralmente a seguinte questão: A agricultura camponesa (des)aparecerá frente às determinações do capital e/ou se (re)criará?

\section{A Agricultura Camponesa (des)aparecerá?}


Em se tratando de estudos clássicos, encontram-se obras que apontam como única saída do campesinato a mudança do camponês para agricultor familiar. Entre elas, estão os escritos de Lênin $(1899 / 1985)$ e $(1918 / 1980)$, e Kaustsky (1986) que explicitam elementos fundamentais para compreender o desenvolvimento da agricultura no capitalismo e as obras de Lamarche $(1993,1998)$ e Abramovay (1992) com defesas que apontam na mesma direção.

Mesmo que Marx não tivesse como objetivo estudar o campesinato do seu tempo, ao pensar a sociedade moderna identificou três grandes classes: "(...) os operários assalariados, os capitalistas e os latifundiários, (...) baseado no regime capitalista de produção" (MARX, 1985, p. 99). Como o camponês trabalha com mão de obra familiar, ele tem outra lógica de produção que não é o lucro, mas primeiro produzir para a sobrevivência e depois vender o excedente no mercado. Marx já tinha chamado essa forma camponesa como pré-capitalista, porque a maneira de produzir os bens agrícolas de autossustento já existia na época feudal.

A partir daí, foi sendo construída a ideia em torno da qual para Marx, o campesinato seria visto como uma sobrevivência ao modo de produção feudal e, portanto, secundário para o estudo em questão, não tendo qualquer papel relevante a cumprir na dinâmica do mundo capitalista.

O livro "O Dezoito Brumário de Luís Bonaparte" de Marx foi interpretado de forma diversa por marxistas e não marxistas. Uma das interpretações está na identificação dos camponeses franceses como incapazes de se constituir enquanto classe visto a impossibilidade de existência de uma representação política própria, pois estavam isolados de um contexto mais amplo. Sem um projeto político próprio que transformasse seus interesses num programa de ação e construísse um governo e Estado próprios, impossível seria constituir-se enquanto classe social.

A grande massa da nação francesa é, assim, formada pela simples adição de grandezas homólogas, da mesma maneira porque batatas em um saco constituem um saco de batatas. (...) na medida em que existe entre os pequenos camponeses apenas uma ligação local e em que a similitude de seus interesses não cria entre eles comunidade alguma, ligação 
nacional alguma nem organização política, nessa exata medida não constituem uma classe. (MARX, 1978, p. 115).

A concepção sobre a incapacidade política dos camponeses, vista por Marx, influenciou na perspectiva teórica de marxistas pós-Marx, que passou à interpretação de que "a natureza do modo de produção capitalista implica uma constante diminuição da população agrícola em relação à população não agrícola" (MARX, apud LENIN 1988, p. 15), alertando no sentido de que, além de não poder ser politicamente independente, o campesinato tendia, a reduzir-se cada vez mais, talvez até seu completo desaparecimento.

Dentre esses autores marxistas que se destacaram no pensamento pós-Marx encontra-se, no início de século XX, Vladimir Lênin. Este autor apresenta seu estudo mostrando a desintegração do campesinato. É de Lenin a ideia de desaparecimento total do campesinato em consequência da grande exploração capitalista, bem como, a desintegração dos camponeses pobres em favor da burguesia rural. A partir de seu olhar para a economia russa concluiu: "O campesinato antigo não se 'diferencia' apenas: ele deixa de existir, se destrói, é inteiramente substituído por novos tipos de população rural, que constituem a base de uma sociedade dominada pela economia mercantil e pela produção capitalista" (LENIN, 1988, p. 113-114).

É neste contexto capitalista que Lênin prevê o início do processo de "extinção do campesinato". Para Lênin "O proletariado rural (...) envolve o campesinato pobre, incluído aí o que não possui nenhuma terra". Esse novo ator social do campo russo, caracterizado pela venda de sua força de trabalho, detém metade dos estabelecimentos agrícolas é assim caracterizado por Lênin:

(...) possui estabelecimentos de extensão ínfima, cobrindo pedacinhos de terra, e, ademais, em total decadência (cujo testemunho patente é a colocação da terra em arrendamento); não pode sobreviver sem vender a sua força de trabalho (= 'ofícios' do camponês sem posses); seu nível de vida é extremamente baixo (provavelmente inferior ao do operário sem terra) (LÊNIN, 1988, p.116).

Lênin, afirma que qualquer camponês que venda, ainda que em tempo parcial, sua força de trabalho a outrem, mesmo se conservar suas 
terras e continuar trabalhando nelas no tempo remanescente, é um proletário e não um camponês. Daí o questionamento: a agricultura camponesa (des)aparecerá? Ou se (re)cria, se (re)significa?

Ariovaldo Umbelino de Oliveira chama atenção no sentido da importância de compreender o papel e o lugar dos camponeses na sociedade capitalista:

[...] Ou entendesse a questão no interior do processo de desenvolvimento do capitalismo no campo, ou então continuarse-á a ver muitos autores afirmarem que os camponeses estão desaparecendo, mas, entretanto, eles continuam lutando para conquistar o acesso às terras em muitas partes do Brasil (OLIVEIRA, 2004. p. 35).

Esta característica de luta pela terra e por reforma agrária é o principal elemento identitário do camponês que indica continuidade e não fim. Esta concepção está contemplada no paradigma da questão agrária defendida e proposta por autores vinculados ao Centro latino Americano de Ciências Sociais $(\mathrm{CLACSO})^{1}$, articulados com a VIA CAMPESINA2 $^{2}$. Diferentemente do que propõe os autores ligados ao Centro Latino Americano de Desenvolvimento Rural (RIMISP) 3 vinculados ao Banco Mundial, cuja ideia central é a defesa da expansão do capitalismo de maneira única e homogênea e cujo paradigma concebe

1 El Consejo Latinoamericano de Ciencias Sociales (CLACSO) es una institución internacional no-gubernamental con status asociativo en la UNESCO, creada en 1967. Actualmente, reúne 542 centros de investigación y posgrado en el campo de las ciencias sociales y las humanidades en 41 países de América Latina, Estados Unidos, Canadá, Alemania, España, Francia y Portugal. O CLACSO se caracteriza enquanto pensamento crítico que defende o aprofundamento e a ampliação da discussão numa perspectiva que confronte o pensamento consensual possibilitando a compreensão das realidades em suas complexidades e diversidades.

2 A Via campesina é um movimento internacional que coordena organizações camponesas de pequenos e médios agricultores, trabalhadores agrícolas, mulheres camponesas, comunidades indígenas e negras da Ásia, África, América e Europa.

3 RIMISP - Red de articulación y generación de conocimiento para el desarrollo de los territorios latinoamericanos. Trabajamos para entender las causas de las brechas territoriales en América Latina, aportar en la elaboración de políticas públicas y en la articulación de actores para un desarrollo territorial más equitativo. Porque las brechas se reducen de manera más efectiva desde los territorios, potenciando al máximo sus capacidades (http://rimisp.org/sobre-rimisp/que-es-rimisp). 
que o futuro para o campesinato está na mudança do camponês para o agricultor familiar.

\section{Um embate de ideias: Agricultura Camponesa se (re)cria e se (re)significa}

De acordo com estudos realizados por Schneider (2003), Kautsky que se baseou na superioridade técnica da grande propriedade, ressaltando que mesmo havendo a expansão das grandes fazendas capitalistas, isto não levaria ao desaparecimento total da pequena propriedade, faz o estudo sobre a formação de Cooperativas. Schneider (2003) destaca que Kautsky enfrenta o debate com Lênin:

Kautsky afirma que o processo de transformação estrutural da agricultura sob o capitalismo não elimina, necessariamente, as pequenas propriedades desde que elas desenvolvam 'formas de trabalho acessório' (que podem ou não estar ligadas à agricultura) que lhes permitam manter sua reprodução social (SCHNEIDER, 2003, p. 105).

Neste sentido, Kautsky assim se pronunciou: “(...) não devemos pensar que a pequena propriedade territorial esteja em vias de desaparecer na sociedade moderna, ou que possa ser inteiramente substituída pela grande propriedade" (KAUTSKY, 1980, p. 178, apud SCHNEIDER, 2003 p. 106).

Nesta perspectiva, é inegável que com o avanço do capitalismo no campo, subordinando o processo agrícola à grande indústria, transformou a família camponesa em consumidora dos produtos oferecidos pelo mercado, o que tem aprofundado a crise na agricultura. Oliveira (2004) coloca que o camponês é aquele que produz para a sobrevivência e vende o excedente. $O$ agricultor familiar vai surgir quando ocorre a modernização da agricultura. É o antigo camponês que passa a se adaptar às determinações do capitalismo na agricultura. $O$ que ocorre neste momento é a inversão do processo em que agora este mesmo agricultor antes conhecido como camponês que produzia para seu autossustento e vendia o excedente inverte seu papel e passa a produzir para o mercado consumindo o excedente. Ou seja, a produção é para o mercado. Como exemplo pode-se citar o Sistema de 
Integração ${ }^{4}$ que cria a dependência. Neste sentido, é preciso compreender o significado de camponês dentro do sistema capitalista, principalmente quando se refere à renda da terra.

[...] o fundamental para o capital é a sujeição da renda da terra, pois a partir daí, ele tem as condições necessárias para sujeitar também o trabalho que se dá na terra. Primeiramente, o capital sujeita a renda da terra e em seguida subjuga o trabalho nela praticado (OLIVEIRA, 1991, p. 49).

Em geral, os autores falam das condições insuficientes de reprodução da família, bem como, das relações de subordinação e chamam atenção para as mudanças que vem ocorrendo no contexto do campo. Na concepção dos Movimentos alinhados à Via Campesina, alguns destes aspectos, permitem pensar que os camponeses/as conseguem se proteger mais das crises capitalistas, porque o jeito de produzir não é tipicamente capitalista. Estranhamente à lógica do capital, o camponês, ao ser um "proprietário que trabalha", de acordo com Wanderley (1989) não está simplesmente preocupado com a reprodução do "capital". Ele estabelece um paralelo entre o trabalho despendido e a satisfação das necessidades da família, condicionando um ao outro. A diferenciação social será medida pelo tamanho da família, que determina sua capacidade de exploração da terra. A extensão das terras cultivadas, portanto, estará em grande medida, associada à capacidade de trabalho da família.

4 O sistema de integração às agroindústrias significa a parceria entre o agricultor familiar com as agroindústrias para desenvolver ações conjuntas de mercado. Nesta parceria o/a agricultor/a disponibiliza a infraestrutura e mão de obra com base no trabalho familiar, o qual deve adotar as orientações previamente discriminadas pela assistência técnica do manejo da criação ou da produção de grãos e, de outro, a agroindústria que é detentora de um vasto complexo industrial fornece insumos em geral tanto para o cultivo da lavoura, como a criação de suínos, aves, gado e produção de leite, até o controle completo da comercialização e beneficiamento da produção. A forte influência da agroindústria no campo estabelece um processo seletivo que enquadra $\mathrm{o} / \mathrm{a}$ agricultor/a nas regras estabelecidas criando um processo de dependência e ou exclusão. Como exemplo podemos citar a produção de suínos através do ciclo completo. "O agricultor desenvolve todas as atividades, desde o nascimento do leitão até a hora de entrega-lo à cooperativa e deve cumprir com todas as exigências do mercado"(KROTH, 1999, p. 52). 


\section{Agricultura Familiar e Agricultura Camponesa: aproximações e diferenças}

Em se tratando da agricultura camponesa, similar à agricultura familiar, a dimensão da família é destacada por diferentes autores e aparece enquanto característica determinante. Como explica Wanderley (1996), "este caráter familiar não é um mero detalhe superficial e descritivo: o fato de uma estrutura produtiva associar família-produçãotrabalho tem consequências fundamentais para a forma como ela age econômica e socialmente". Wanderley (1996, p.2) esclarece que a denominação genérica de agricultura familiar abrange múltiplas formas de agricultura praticadas. A forma de tradição camponesa de cultura faz parte de uma dessas variações. Segue a linha de formação "famíliaprodução-trabalho".

Neste sentido, entende-se que a agricultura camponesa pode ou não estar inserida no universo da agricultura familiar, o que não se pode afirmar o contrário. Tem-se dito que uma das questões que diferencia a agricultura camponesa das demais está no seu jeito de se inserir no contexto global do capital, seus objetivos econômicos e as experiências de sociabilidade que ela possibilita. Mas afinal isto dá conta de diferenciar ou identificar agricultura camponesa e familiar? É suficiente? Que elementos diferenciam ou identificam a agricultura camponesa e familiar? Tais questões persistem e carecem de maiores estudos e aprofundamentos.

Antuniassi (1999) ao explicitar o conceito de agricultores familiares, mostra que uma das características principais é a produção voltada para o mercado, mesmo que haja a produção de subsistência ou de autossustento, o foco da produção é a venda comercial dos seus produtos. Aqui também vale destacar "o uso de mão de obra assalariada e o aprimoramento do conhecimento técnico para a agricultura" (ANTUNIASSI, 1999). Oliveira entende que "o processo de desenvolvimento do capitalismo na agricultura de nossos dias está marcado pela sua industrialização" (OLIVEIRA, 1991, p. 23). O movimento dos camponeses no Brasil passa a se constituir enquanto tentativa de resgate da condição de camponês autônomo frente às determinações e às imposições do capital na agricultura. 
Um dos aspectos comuns entre agricultura familiar e agricultura camponesa é o elemento familiar. Neste sentido, vários autores apresentam a família enquanto elemento indispensável para análise dos estudos sobre a questão camponesa. Entre eles, destacam-se: (MENDRAS, 1976), (CHAYANOV apud SILVA 1981). Carvalho (2006), ao problematizar sobre a agricultura camponesa, destaca a família como um elemento constitutivo dessa identidade. De acordo com Sandroni (1985), o campesinato pode ser definido como: "O conjunto de grupos sociais de base familiar que, em graus diversos de autonomia, se dedica a atividades agrícolas em glebas determinadas" (SANDRONI, 1985, p. 45).

Shanin (2005) destaca uma variedade de características economicamente relevantes. Entre eles, o padrão efetivo de controle da terra, expresso na propriedade familiar, e os "direitos de posse" diferem da propriedade legal dos não camponeses contemporâneos. O autor insiste em chamar atenção para a importância de que "os camponeses não podem ser, de fato, compreendidos ou mesmo adequadamente descritos sem sua estrutura societária mais geral" (SHANIN, 2005, p. 5).

Chayanov é o autor que elaborou a teoria da unidade econômica camponesa. Estuda o aumento de unidades familiares bem como a manutenção da unidade econômica camponesa ou a formação de cooperativas coletivas. Este autor chama atenção no sentido de que a unidade de produção familiar agrícola é regida por princípios diferentes da unidade de produção capitalista. "Na economia agrícola familiar, a família, equipada com meios de produção, emprega sua força de trabalho no cultivo da terra, e recebe como resultado de um ano de trabalho certa quantidade de bens" (CHAYANOV apud SILVA, 1981, p. 17).

Há outra dinâmica nesta lógica camponesa. Na sua grande maioria, os autores acima citados convergem nos elementos característicos da agricultura camponesa: a família, trabalho e o acesso a terra. Mendras (1976), quando fala de uma relativa autonomia face à sociedade global, destaca a importância estrutural dos grupos domésticos, enquanto um sistema econômico de "autarquia relativa, uma sociedade de interconhecimentos e a função decisiva dos mediadores entre a sociedade local e a sociedade global" (MENDRAS, 1976, apud WANDERLEY, 1999, p. 52). Nesse determinado tipo de 
economia, o resultado do trabalho obtido pela família é um todo indivisível, o trabalho desenvolvido pela família se diferencia da atividade do capitalista e do proletário. O modo de produção camponês caracteriza-se como sendo um sistema produtivo diferenciado que tem como objetivo a reprodução familiar (WANDERLEY, 1989, p. 24).

Para Carvalho (2005), o fato de se diferenciar das estruturas capitalistas que têm como centralidade o lucro, a agricultura camponesa, centrada na reprodução, não significa "a exclusão do lucro na realidade camponesa". O que se coloca como prioridade nesta situação são as expectativas em relação às necessidades e às condições reprodutivas, que estão em primeiro lugar. Seria ingenuidade dizer que o camponês, a camponesa não aspira melhorar suas condições, visando agregar elementos do capital como meios de produção. Diferentemente dos empreendimentos agrícolas capitalistas que acumulam para aumentar o lucro, "a unidade camponesa acumula para tornar mais eficiente essa reprodução" (CARVALHO, 2005, p.183).

Desta forma é aceitável a concepção de que, "o camponês é expresso como categoria social a partir de relações capitalistas de produção, mantendo, entretanto os valores do modo de vida camponês oferecendo resistência às mudanças impostas pelo mercado" (OLIVEIRA, 1988, p 23). Neste sentido, a concepção sobre agricultura camponesa ganha importância, sobretudo enquanto campo de luta permanente que se coloca frente às imposições do capital, fazendo emergir diferentes sujeitos no campo, que por vezes dada às dinâmicas de resistência e enfrentamento, retornam a terra.

[...] Se a mundianização da economia capitalista traz à tona novos sujeitos sociais e novas articulações, igualmente e contraditoriamente, traz também à tona a luta de novos personagens sociais: basta olharmos para o México, e lá estão os zapatistas em luta. Com certeza a história não acabou, e muito menos a utopia (FERNANDES, 1996, p. 11).

Para Fernandes (1996), imerso à realidade desigual de exploração e de exclusão nasce um movimento de (re) criação do campesinato que se efetiva na luta pela terra e pela reforma agrária. É, sobretudo, na ocupação do latifúndio que brota uma nova territorialização para a vida camponesa. 
[...] é no interior desse processo desigual que se desenvolvem a exploração econômica, a exclusão cultural e a dominação política, gerando os conflitos e as mais diversas formas de resistência. No interior desse processo formam-se diferentes movimentos sociais que inauguram novas situações, desenvolvem outros processos (FERNANDES, 1996, p. 25).

Com a criação de movimentos populares camponeses nascem outras concepções sobre a vida camponesa, bem como os processos são ressignificados e pensados a partir de contextos e experiências diversificadas. 


\section{Agricultura Camponesa na perspectiva do MMC}

O MMC, assim como outros Movimentos que se articulam com a VIA CAMPESINA está permanentemente ressignificando os conceitos a partir de cada contexto e de cada realidade onde os sujeitos vivem. Constroem-se uma identidade própria a seus modos de viver. Silva (2011) explica que:

a identidade camponesa é o reconhecimento do que o identifica, do que lhe é próprio. Ela é caracterizada pelo modo de viver, pelo modo de se relacionar com outros grupos sociais e com a natureza, através do uso que se faz dela, expressos pelos hábitos alimentares e comidas típicas, pela cultura, pela música, pelas danças, pela mística e religiosidade, pelo jeito de produzir e de cuidar da terra.

Continua o autor:

Para o camponês e a camponesa, a terra é o lugar de reproduzir e cuidar da vida. As sociedades e comunidades tradicionais, nas quais se inserem os indígenas, os quilombolas, os sertanejos, os caiçaras, os caboclos, os extrativistas e, por fim, o campesinato em toda sua sociodiversidade, caracteriza-se pela sua dependência em relação aos recursos naturais.

Silva (2011) mostra que:

É no aprendizado sobre o funcionamento dos ciclos naturais de quando chove ou faz seca, sobre as plantas que ali crescem ou os animais que por ali vivem - que nasce e se desenvolve o conhecimento sobre essa diversidade, e que tradicionalmente é repassado de uma geração a outra. Assim se constrói "o modo de vida" de cada povo ou comunidade tradicional e são definidos os seus territórios, espaços onde cada grupo se reproduz econômica e socialmente, auto identificando-se com "o lugar", por pertencer a uma cultura distinta da demais. Assim é o camponês brasileiro (SILVA, 2011 , p. 453).

Em se tratando da designação camponesa, quando se pensa a partir das mulheres, há uma complexidade que está colocada, pois o fato de terem sua origem no meio rural não às faz delas imediatamente camponesas. Sendo de famílias que no passado foram agricultoras tampouco lhes assegura para sempre o qualificativo de agricultora, de 
camponesa. Como escapar de um tratamento naturalizado e determinístico de tais conceitos? Que realidade foi construída pelas mulheres deste Movimento em resposta às determinações do capital? De que perspectiva camponesa e de que noção de resistência se refere este Movimento?

De acordo com Cinelli y Jahn (2011) a concepção de camponesa no MMC está associada à resistência frente às imposições sistêmicas. São "camponesas, quando decidem não mais seguir um modelo de agricultura ditado pelas empresas com utilização de agrotóxicos [...]" (CINELLI y JAHN 2011 , p. 92).

Renk (2001), ao abordar sobre a trajetória das mulheres agricultoras, num contexto da agricultura no oeste catarinense, mostra que, contrariamente, ao fato do campesinato ter sido considerado como estático, imutável, a realidade construída pelas mulheres agricultoras tem mostrado um campesinato dinâmico, que interage com a sociedade apresentando diferentes estratégias de reprodução da vida.

Neste sentido, camponeses/a adquirem sinônimo de agricultores/as que dispondo de pequenas unidades produtivas, utilizam-se do trabalho familiar na produção, destacando-se como sua principal característica a diversidade. Encontrando como categoria nucleante os conceitos terra, trabalho e família como elementos definidores de sua campesinidade (WOORTMANN, 1990).

Valdete Boni (2013) explica que:

na França, a denominação camponês sempre foi muito utilizada para demarcar um tipo de agricultura baseado na exploração familiar. Se o termo, hoje, não é mais utilizado com a mesma ênfase, não é porque o camponês tenha desaparecido, mas porque foi substituído pela denominação de "agricultor familiar".

Entretanto, a autora mencionada mostra que:

as camponesas ligadas ao MMC não concordam com essa visão de que o camponês "está um passo atrás" em relação aos agricultores familiares. Não consideram o campesinato um modo atrasado ou com menor inserção no mercado. O diferenciam da agricultura familiar de campesinato, sendo este último compreendido como um modo de produção diferenciado, mas nunca inferior. 
De acordo com Vieira (2009), o conceito de camponês possui diferentes significados para os Movimentos da VIA CAMPESINA, não havendo nenhum tipo de consenso entre estes. O que existe são características comuns visto que se trata de trabalhadores (as) do meio camponês e a identificação maior se deve à relação com as lutas sociais das Ligas camponesas ${ }^{5}$ entre outras que ocorreram em diferentes tempos e lugares.

O conceito sobre camponês (camponesa) para o Movimento é uma construção a partir das práticas exercidas em suas propriedades. Em geral, não se destaca a posição específica de cada membro da família, entretanto, as mulheres da roça que estão aí inseridas, desempenham diferentes funções relativas ao processo de trabalho da agricultura familiar/camponesa.

Para compreender as mulheres deste Movimento é preciso situá-las no contexto da família. Visto que o núcleo familiar, é constituído de sujeitos diferenciados, fundamenta-se no trabalho familiar, na produção para autoconsumo, comercialização, em que todos os membros cooperam, sendo que a maioria das famílias vive e sobrevive com pouca terra, diferenciando-se assim da agricultura latifundiária, caracterizada pelas grandes áreas, pelo monocultivo e pelo trabalho assalariado. Entretanto, isto não significa dizer que ausência de mulheres cujas famílias estão integradas à lógica das agroindústrias locais, com maior poder aquisitivo.

\subsection{Significados do termo Camponês para o MMC}

A partir do ano 2000, quando em nível nacional, os movimentos específicos e autônomos de mulheres do meio rural, buscavam construir uma unidade nacional em torno de bandeiras comuns, o termo camponês é incorporado no Movimento, como temática de estudo que por sua vez, fundamentará as concepções e as perspectivas assumidas pelas mulheres e pelo movimento. Oficialmente, em 2004, o termo camponesa é assumido enquanto expressão de unificação dos movimentos autônomos de mulheres do meio rural, que juntam em suas

\footnotetext{
${ }^{5}$ A este respeito pode ser visto os estudos de Porto e Siqueira (1994, p. 79) que tratam sobre campesinato e pequena produção desde a década de 1950.
} 
bandeiras de lutas, as perspectivas de gênero, de classe, de geração o que não significa um processo que não se fez sem a ausência de críticas e de contestações.

Para $O$ MMC, o termo camponês, camponesa, adquiriu relevância determinando na escolha do seu próprio nome: Movimento de Mulheres Camponesas - MMC. Tal relevância é decorrente de diferentes significados para este Movimento. A reflexão de que, na origem, 'camponês' seria aquele/a que, vivendo em regime de economia familiar cooperada, com pouca terra, através do trabalho, produz sua própria alimentação, elemento determinante para o autossustento e a renda. E, produzir alimentos saudáveis é uma das bandeiras de luta do movimento.

Outro significado encontrado pelo Movimento, em relação à palavra camponês, camponesa, se refere a todos/as que estão no campo: trabalhadores/as rurais, meeiros/as, ribeirinhos/as, agregados/as, pescadores/as artesanais, quebradeiras de coco, cortadores/as de cana, entre outros. $O$ argumento que também adquire significado para a expressão camponesa no MMC está na história de resistência do campesinato frente à dominação do capital nos diferentes modos de produção.

O MMC vem construir junto com as mulheres camponesas o sentido político da resistência organizada, da resistência oculta, do cotidiano das mulheres camponesas marcado pela resistência e pela luta permanente em defesa da vida. Como as mulheres foram sábias ao longo da história! Sabem muito bem a importância, os mistérios e os segredos relacionados à vida! Por isso, mantém este poder de resistência, o poder que vem de dentro, de base, de organização, de um projeto de vida e de luta por uma nova sociedade (MMC, 2007).

As lutas de resistência e de enfrentamento ao modelo de agricultura química se intensificam nesse período, principalmente pela investida do agronegócio no meio rural brasileiro, trazendo consequências para as famílias que vivem em regime de economia familiar, que se vêm cada vez mais prejudicadas pela falta de incentivo publico na agricultura e que de certa maneira, não resta alternativa para as mulheres senão a resistência.

De acordo com documentos internos do movimento, em meio as suas reivindicações e lutas sociais a agricultura camponesa é entendida 
enquanto "Forma de recuperar as sementes crioulas, trocar suas experiências, estudar maneiras de, sem maior agressão ao meio ambiente, tirar da terra o autossustento e a renda necessária”. (...) (Arquivos internos do MMC s/d).

Registros do MMC, afirmam que quando a mulher camponesa toma em suas mãos, sua própria vida e sua própria realidade, "permitindo com seu olhar feminista perceber que o equilíbrio da natureza depende centralmente, da forma com que tratamos a terra, (...) e a partir desta concepção, busca produzir o alimento que vai para a mesa de todos". (Arquivos do MMC s/d).

Para as mulheres do Movimento, produzir as condições de sobrevivência, faz parte de seu papel enquanto agricultoras. Ao fazer isso essas mulheres propõem repensar um horizonte camponês, através do qual não será possível conquistá-lo sem o acesso a terra, sem a reforma agrária, sem o acesso a renda, sem a divisão das tarefas e sem a autonomia das mulheres, elementos considerados indispensáveis para a continuidade e permanência no campo. É neste sentido que o movimento considera fundamental que as mulheres lutem contra o modelo químico de agricultura, cuja produção é baseada no de insumos e de agrotóxicos, na padronização dos alimentos, entre outros.

Para o MMC, o modelo praticado pelos grandes empresários do agronegócio na fase do capitalismo globalizado está colocado como o principal responsável pelo empobrecimento, pelas desigualdades sociais e pela expulsão das famílias e das jovens, que, não encontrando perspectivas deixam o campo em busca de trabalho, de estudo, de renda e de novas sociabilidades, atributos necessários para uma vida melhor. Pois não basta apenas desenhar boas estratégias, elaborar bons projetos, fazem-se necessárias condições práticas e efetivas para implementá-las no cotidiano das famílias.

A perspectiva de agricultura camponesa, para o MMC, ultrapassa a ideia de produção econômica/agrícola ou autossustento e renda, e configura-se enquanto espaço social de construção de vivências, de valores, de autonomia e de identidade social que se diferencia do mundo urbano, mas que com ele dialoga e estabelece relações. Daí a ressignificação dos próprios conceitos a partir das dinâmicas vividas.

\section{Considerações finais}


Conforme se percebe através deste ensaio, contrariamente ao que vem sendo afirmado historicamente, o modo de vida camponesa, ao invés de desaparecer, se (re)cria, se (re)inventa e se (re)coloca nos diferentes cenários enquanto modo de vida, de resistência e de enfrentamento às determinações do Capital. Há um processo histórico em curso, que é de reinvenção e de recriação das perspectivas camponesas, enquanto modos de vida. As referências bibliográficas são expressões deste dianamismo camponês que permanentemente coloca novas questões a serem estudadas, pesquisadas. Os conceitos, as categorias analíticas tendem a serem alteradas na medida em que novas pesquisas vão colocando perguntas novas e dúvidas a cerca de tais temáticas. As experiências dos Movimentos Sociais, a exemplo do MMC, constituem-se enquanto espaços privilegiados que problematizam os processos de vida das mulheres e de suas famílias no campo, bem como motivam os sujeitos a encontrarem alternativas para uma vida mais digna em se tratando de agricultura camponesa. $O$ camponês diferentemente do que foi anunciado por alguns clássicos, ao invés de adapatarem-se à lógica do Capital como única forma de continuar existindo, fazem da luta contra o capital razão da continuidade e do sentido de sua existência.

\section{REFERÊNCIAS}

ABRAMOVAY, Ricardo. Paradigmas do capitalismo agrário em questão. São Paulo: Hucitec, 1992.

ANTUNIASSI, M. H. R. Mundo rural e agricultura no Brasil. In: Agruras e prazeres de uma pesquisadora: ensaios sobre a sociologia de Maria Isaura Pereira de Queiroz. Org: KOSMINSKY, E. V. Marília: Unesp Marília Publicações, 1999. BECKER, H. S. Métodos de pesquisa em ciências sociais. São Paulo: Editora HUCITEC, 1999 (quarta edição).

CARVALHO, Horácio Martins de. Ah! Jacques, Jacques... Liberte-se desse Encantamento Milenar, 2005. Disponível em: http://www.coptec.org.br. Acesso em: 27.06.2015. 
CINELLI, Catiane y JAHN, Elisiane de Fátima. A constituição de identidades camponesa e feminista no Movimento de Mulheres Camponesas. Revista Espaço Acadêmico - $N^{0} 117$. Fevereiro de 2011. Ano X - ISSN. 1519-6186

CHAYANOV, A. V. 1981. Sobre a teoria dos sistemas econômicos não capitalistas. In: SILVA, J.G.; STOLCKE, V. A questão agrária. São Paulo: Brasiliense, 1981.

CLACSO. Disponível em http://www.clacso.org/ Acesso em: 20.04.2016.

FERNANDES, Bernardo Mançano. MST: espacialização e territorialização. São Paulo: Hucitec, 1996.

LAMARCHE, Hugues. (coord.) A agricultura familiar: uma realidade multiforme. Trad. Jehovanira C. de Souza. Campinas: Editora da Unicamp, 1993.

(coord.) A agricultura familiar: do mito à realidade. Trad. Jehovanira C. de Souza. Campinas: Editora da Unicamp, 1998.

LENIN, Vladimir Ilitch. O desenvolvimento do capitalismo na Rússia: o processo de formação do mercado interno para a grande indústria. 3 . ed. São Paulo: Nova Cultural, 1988.

MOVIMENTO DAS MULHERES CAMPONESAS. Sementes de vida nas mãos das mulheres camponesas; Campanha pela produção de alimentos saudáveis. Disponível em: <www.mmcbrasil.org.br> Acesso em 20/04/2016.

KAUTSKY, Karl. $A$ questão agrária. Tradução de C. Iperoig. São Paulo: Proposta Editorial, 1980.

KROTH, Sirlei Antoninha. Atalhos da luta: trajetória e experiências das mulheres agricultoras e do Movimento de Mulheres Agricultoras de Santa Catarina, 1983-1993. São Paulo, 1999. (Dissertação de Mestrado). Pontifícia Universidade Católica de São Paulo, São Paulo, 1999. 
MARX, K. O 18 Brumário. Rio de Janeiro: Paz e Terra, 1978.

O capital. v. II e III. São Paulo: Abril Cultural, 1985 (Coleção Os Economistas).

MENDRAS, Henri. Sociétés paysannes. Paris, A.Colin, 1976.

OLIVEIRA, Ariovaldo Umbelino de. A geografia das lutas no campo. São Paulo: Contexto, 1988.

A agricultura camponesa no Brasil. São Paulo: Contexto, 1991.

Os mitos sobre o agronegócio no Brasil. In: Encontro Nacional do MST, 12, 2004, São Miguel do Iguaçu-PR. Disponível em: Acesso em: 20 de fevereiro de 2004.

Os mitos sobre o agronegócio no Brasil. In: Encontro Nacional do MST, 12, 2004, São Miguel do Iguaçu-PR. Disponível em: Acesso em: 11 de agosto de 2015.

PLOEG, J. D. Camponeses e impérios alimentares: lutas por autonomia e sustentabilidade na era da globalização. Editora UFRGS: Porto Alegre, 2008.

PORTO, Maria Stela G. e SIQUEIRA, Deis E. A pequena produção no Brasil: entre os conceitos teóricos e as categorias empíricas. Cadernos de Sociologia. Porto Alegre: PPGS/UFRGS, vol. 6, p. 76-88. 1994.

WANDERLEY, Maria de Nazaré Baudel. Em busca da modernidade social. Uma homenagem a Alexander V. Chayanov. Unicamp, Departamento de Ciências Sociais, 1989. Trabalho não publicado.

M. N. B. Raízes históricas do campesinato brasileiro. XX Encontro Anual da ANPOCS. Caxambu: 1996.

WOORTMANN, E. F. O saber tradicional camponês e inovações. In: $O$ campo no século XXI: Território de vida, de luta e de construção da justiça social/Ariovaldo Umbelino de Oliveira, Marta Inez Medeiros 
Marques (Orgs). São Paulo: Editora Casa Amarela e Editora Paz e Terra, 2004.

RENK, Arlene. Mulheres camponeses: experiência de geração. In: Antonio Morga. (Org.). História das Mulheres de Santa Catarina. $1^{\mathrm{a}}$ ed. Florianópolis/ Chapeco: Letras Contemporânea/ Argos, 2001, v. 1, p. 218-248.

RIMISP. Disponível em <http://rimisp.org/sobre-rimisp/que-esrimisp >. Acesso em: 20 abr. 2016.

SANDRONI, Paulo. Dicionário de Economia. São Paulo: Abril, 1985.

SILVA, Marciano Toledo da.Violação de direitos e resistência aos transgênicos no Brasil: uma proposta camponesa. In: ZANONI, Magda; FERMENT, Gilles (orgs). Transgênicos para quem? Agricultura, Ciência e Sociedade. Brasília: MDA, 2011.

SHANIN, Teodor. A definição de camponês: conceituações $e$ desconceituações - o velho e o novo em uma discussão marxista. Revista NERA - Presidente Prudente. Ano 8, nº. 07. Julho/Dez de 2005.

SHENEIDER, Sérgio. Teoria social, agricultura e pluriatividade. Revista Brasileira de Ciências Sociais, v. 18, n. 51, p. 99 a 120, fevereiro de 2003.

Submetido em 29/05/2016

Aprovado em 20/08/2016

\section{Sobre as Autoras}

Sirlei Antoninha Kroth Gaspareto

Doutoranda em Desenvolvimento Regional (PPGDR/UNISC).

Email: Sirlei@unochapeco.edu.br

\section{Erica Karnopp}

Professora Doutora em Geografia pela Universität Tübingen - Alemanha. Docente e Pesquisadora do Departamento de História e Geografia e Programa de Pós-Graduação em Desenvolvimento Regional - Mestrado e Doutorado da UNISC.

E-mail: erica@unisc.br 
A Agricultura Camponesa (des)aparecerá frente às determinações do capital e/ou se (re)criará?

\section{Cidonea Machado Deponti}

Professora Doutora em Desenvolvimento Rural (PGDR/UFRGS). Docente e Pesquisadora do Departamento de Ciências Econômicas e Programa de Pós-Graduação em Desenvolvimento Regional - Mestrado e Doutorado da UNISC.

Email : cidonea@unisc.br 